In: Infancy : the official journal of the International Society on Infant Studies, Volume 23, Issue 6 (2018) , S. 820-832 ; EISSN: 1532-7078; https://doi.org/10.1111/infa.12259; Submitted Manuscript

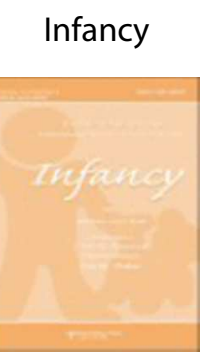

\title{
Shape but not color facilitates two-year-olds' search performance in a spatial rotation task
}

\begin{tabular}{|r|l|}
\hline Journal: & Infancy \\
\hline Manuscript ID & HIFC-2017-0114.R2 \\
\hline Manuscript Type: & Research Article \\
\hline Keywords: & $\begin{array}{l}\text { spatial search, object displacement task, toddlers, spatial rotation task, } \\
\text { object permanence }\end{array}$ \\
\hline \multicolumn{2}{|l}{} \\
\hline
\end{tabular}

SCHOLARONE ${ }^{m}$

Manuscripts 
Running head: TWO-YEAR-OLDS' SPATIAL SEARCH

\begin{abstract}
Children younger than three years of age often fail to track hidden objects that are rotated together with identical hiding containers, which might be due to relatively complex paradigms. We examined whether 2-year-olds $(N=28)$ are already able to track spatial rotations (i.e., by $90^{\circ}$ and $180^{\circ}$ ) if the task is facilitated by increasing the visual discriminability of the hiding containers by means of different shapes and different colors. Children performed above chance level in all conditions except for the condition in which containers had the same color and shape and were rotated by $180^{\circ}$. Moreover, children found the hidden object more often when the containers had different - as compared to identical shapes, whereas performance was similar when the containers had the same or different colors. Furthermore, their performance was better after $90^{\circ}$ rotations than after $180^{\circ}$ rotations and children in all conditions showed an inhibition bias. Our findings suggest that 2-year-olds are already able to track spatial rotations if the task is kept simple and focuses solely on the ability of interest. In addition, young children use shape - rather than color - as a salient dimension in spatial rotation tasks.
\end{abstract}


Running head: TWO-YEAR-OLDS' SPATIAL SEARCH

\section{Shape but not color facilitates two-year-olds' search performance in a spatial rotation \\ task}

The question of when infants actively search for hidden objects was first addressed by Piaget (1955) who observed this behavior in children from the age of 6 to 8 months (see also

Diamond \& Lee, 2000). Searching for a hidden object requires object permanence, which means the understanding that an object continues to exist even if it is temporarily out of sight. Object permanence can be found by means of implicit measures in infants as young as 2 months old (Hespos \& Baillargeon, 2001).

Another important prerequisite to successfully find temporarily hidden objects is object individuation, that is, the ability to track objects through time and space, and to recognize them as familiar (Xu, Carey, \& Quint, 2004). From the age of 12 months, infants use object features to individuate objects: For instance, they expect two objects, differing in shape, color, or type, to be two distinct objects, even if they have seen them only consecutively and disappearing at the same location. Younger infants, in contrast, rather rely on spatio-temporal information, that is, they expect only one object if two different objects share the same location (e.g., Xu \& Carey, 1996; Van de Walle, Carey, \& Prevor, 2000). However, other studies found the ability to use featural information in object individuation in infants as young as 4.5-months old (e.g., Wilcox \& Baillargeon, 1998a, b). The discrimination between feature- and place-based strategies can also be found in spatial search tasks. While 1year-olds rather rely on the initial location of an object in their spatial search, 3-year-olds instead use features of the hiding environment to retrieve the object (Haun, Call, Janzen, \& Levinson, 2006).

A more advanced task than simply retrieving hidden objects is to track moving objects that are temporarily occluded. Infants at the age of 2.5 months have a rudimentary grasp of the location of a hidden object that is moving along a fixed track: They expect it to become visible between two occluders and to disappear when it moves behind the occluders (Aguiar 
\& Baillargeon, 1999). Thus, the ability to anticipate the movement of a single hidden object, as assessed by means of gaze durations, emerges very early. In active, predictive search - that is, infants observe a moving object, which is then occluded, and reach to the point where they anticipate the object to reappear - this ability emerges about two months later (Rosander \& von Hofsten, 2004). However, one shortcoming of predictive search tasks is that young children might be able to infer the final location of the object - but possess less inhibitory control and may therefore be unable to suppress a more dominant action (e.g., reaching for the closest location; Diamond, 1990).

Object displacement tasks are a specific kind of spatial search task in which an object is hidden at one of multiple hiding locations (e.g., beneath one of three containers), which are then moved together with the object. These tasks become more difficult (1) the longer the movement takes as this requires maintaining the mental representation of the moving object in memory for a longer time, and (2) the more potential hiding locations are involved as this requires more attentional resources (Hespos, Gredebäck, von Hofsten, \& Spelke, 2009). Object displacement tasks may involve spatial transpositions or spatial rotations. In spatial transpositions, the hiding containers interchange their locations by being moved manually by the experimenter, while in spatial rotations, the containers are usually placed on a board that is rotated along a horizontal axis together with the containers (for an example, see Fig. 1). Several (implicit or explicit) strategies might be applied to find the hidden and then moved object. First, individuals might simulate the movement in their imagination by mental rotation. This can be done either by imagining the movement of the target object while keeping one's own perspective (i.e., object-based transformation; Marmor, 1975) or by imagining moving oneself around the scene containing the object of interest (i.e., egocentric transformation; Estes, 1998). Even young infants appear to be able to execute mental rotation (e.g., Frick \& Möhring, 2013; Moore \& Johnson, 2008). Second, individuals might visually track the hiding container with their gaze - a strategy which was observed already in 2-year- 
Running head: TWO-YEAR-OLDS' SPATIAL SEARCH

olds when they tracked a moving object that was partially occluded (Butler, Berthier, \& Clifton, 2002). This approach is enhanced if individuals additionally use external cues, such as the featural characteristics of the containers (e.g., their color) or their configuration. The containers' configuration might be a particularly useful cue as it changes after a $90^{\circ}$ rotation: previously side by side arranged containers appear then one behind the other, and vice versa. However, the question of whether and which featural information young children use in spatial rotation tasks is not yet fully resolved.

In the present study, we investigated the ability of 2-year-olds to track a hidden rotated object and examined whether they would benefit from distinct visual characteristics of the hiding containers and from different rotation angles. Results concerning the development of the ability to track spatial rotations are not fully conclusive so far, which can - at least in part - be attributed to the different paradigms that have been used. In our view, a task assessing an ability of interest should be designed in the simplest possible way, only addressing the particular ability and not adding further difficulties to the task, for instance by increasing cognitive load. Thus, in spatial rotation tasks, more hiding locations, longer rotation movements, and indistinguishable hiding containers likely add to task difficulty, potentially masking the spatial rotation ability of young children.

In previous studies involving spatial rotations, 30-month-olds were presented with three containers on a rotating board, beneath one of which an object was hidden. Children performed on chance level after $360^{\circ}$ rotations and even significantly below chance level after $180^{\circ}$ rotations. In the latter case, children searched systematically more often at the initial hiding location, where they had last seen the object (Barth \& Call, 2006; Herrmann, Call, Hernandez-Lloreda, Hare, \& Tomasello, 2007; see also Sophian, 1984). In another study by Ebersbach and Nawroth (2016), only two containers and $90^{\circ}$ instead of $360^{\circ}$ rotations were involved to simplify the task. Accordingly, 30-month-olds found the hidden object after $180^{\circ}$ and $90^{\circ}$ rotations significantly more often than expected by chance. Thus, fewer potential 
hiding locations and rotation angles that change the configuration of the containers (i.e., $90^{\circ}$ ) seem to make the task easier for the children (cf. Berthier et al., 2001; Boudreau \& Bushnell, 2000).

So far, identical containers have often been used as hiding locations, preventing children from the use of external characteristics, such as color or shape of the containers. However, one might speculate that by using identical hiding containers children's performance in previous studies might have been confounded with their inability to discriminate the containers, which might lead to a decreased performance in these tasks. In fact, some studies have shown that children profit from visually distinct containers in spatial search tasks. For instance, 42-month-olds tracked the occluded transposition of containers that had different shapes and colors, and found the hidden object significantly more often beneath the corresponding container than expected by chance when containers could be discriminated (Haun et al., 2006). Moreover, 40-month-olds benefitted in a spatial rotation task, involving $180^{\circ}$ rotations, from containers that were marked with different stickers, while they performed at chance level with containers that had different colors only (Okamoto-Barth \& Call, 2008). When 22-month-old children observed that an object was hidden beneath one of four containers that were placed in a rectangle around them in the room, and children were thereafter rotated with covered eyes, they benefitted in their search when containers were visually discriminable (i.e., different colors and different stickers) as well, and found the objects more often than children in the control condition with identical containers (GarradCole, Lew, Bremner, \& Whitaker, 2001). Nevertheless, young infants appear to use less object features in their spatial search than older children or adults and rely instead more strongly on spatial cues, such as the initial location of the hidden object (Haun et al., 2006; Oláh, Kupán, Csík, Király, \& Topál, 2015).

One attempt to provide further evidence that visual discriminability enables young children to track invisible spatial rotations comes from Ebersbach and Nawroth (2016). They 
Running head: TWO-YEAR-OLDS' SPATIAL SEARCH

used a spatial rotation task in which an object was hidden in view of 30-month-olds beneath one of two containers that were located on a rotating board. The containers had either the same or different colors and were rotated by $90^{\circ}$ or $180^{\circ}$. Children did not generally profit from visually different containers in terms of different colors compared to same colors, but performed above chance in all conditions. However, color prevented children from committing an inhibition bias. Such an inhibition bias may occur after $90^{\circ}$ rotations in incorrect trials only, when the spatial configuration of the containers changes from a horizontal one (i.e., one container on the left, the other on the right) to a vertical one (i.e., one container closer to the child, the other one farther away). Children showing this bias choose the container that is located closer to them after the rotation significantly more often than expected by chance compared to the container that is located farther away - as they cannot inhibit their tendency to reach for the closer one (Call, 2001). In accordance with the visual discriminability hypothesis, children in the study by Ebersbach and Nawroth (2016) showed an inhibition bias in incorrect trials in the $90^{\circ}$ rotation condition only if the containers had the same color, while no such bias emerged when children were presented with containers of different colors. This can be taken as a hint that 30-month-olds profit from visually different containers in spatial rotation tasks at least with regard to this inhibition bias. The absence of a main effect of color on 30-month-olds general performance might be explained by ceiling effects as children's performance was relatively high in all conditions.

Another explanation for the absence of the main effect of color in the study by Ebersbach and Nawroth (2016) would be that color, at least for young children, might be not a very salient cue. A more salient cue, in contrast, might be shape (Fernandez \& Richman, 1979; Kagan \& Lemkin, 1961; Wilcox, 1999). This assumption is tested in the present study by varying not only the color but also the shape of the containers that serve as hiding locations in a spatial rotation task. In addition, the rotation angle was varied $\left(90^{\circ}\right.$ versus $\left.180^{\circ}\right)$. The central aim was to provide further insights into the questions of whether young children profit 
from visually discriminable containers and configurations in a spatial rotation task and, therefore, solve this task at a younger age than one would expect based on previous findings (i.e., younger than 30 months: Barth \& Call, 2006; Ebersbach \& Nawroth, 2016). Visual discriminability was manipulated with regard to shape and color. We expected that 2-yearolds would find the hidden object after spatial rotation more often (1) if the object was hidden beneath differently shaped containers instead of beneath containers of the same shape, and (2) if the containers were rotated by $90^{\circ}$ instead of by $180^{\circ}$, whereas (3) color should not be a salient cue for the children and thus would not affect search performance. Finally, we expected that an inhibition bias would occur for containers with the same color / shape but not when containers' appearance differed.

\section{Method}

\section{Participants}

Participants were 29 children between 22 and 26 months old, recruited via day care centers, mother-child courses (e.g., gym courses), and advertisement in the local newspaper in a medium-sized town in Germany. One boy was excluded from the analyses as he did not comply with the task instructions and tried instead to play hide and seek with the experimenter. The remaining sample included 28 children (12 girls, 16 boys, mean age: $M=$ 24.1 months, $S D=1.5$ months).

\section{Material}

Opaque plastic cups served as hiding containers. They were either orange or blue, and had either a round (diameter: $8.2 \mathrm{~cm}$, height: $12 \mathrm{~cm}$ ) or an angular shape (breadth: $6 \mathrm{~cm}$ x depth: 6 $\mathrm{cm} x$ height: $6 \mathrm{~cm}$ ). In order not to enhance the complexity of the procedure, and as we expected no advantage for one particular color or shape, cups in the same color condition were always orange and cups in the same shape condition were always round. In each trial, two inverted cups were placed in a distance of $10.4 \mathrm{~cm}$ from each other at two opposite edges on a round rotating board (see Figure 1). The board (diameter: $38.4 \mathrm{~cm}$ ) rested on wheels to 
Running head: TWO-YEAR-OLDS' SPATIAL SEARCH

allow rotation movements. It was placed on a table with its front edge in a distance of about $10 \mathrm{~cm}$ from the child, sitting on a chair on that table. The hidden objects were small toys that fit into the cups. A camera (PanasonicHC-V550) with a tripod served to record the procedure.

\section{Design and Procedure}

The experiment followed a 2 (discriminability concerning the shape of the hiding containers: same versus different shapes) $\mathrm{x} 2$ (discriminability concerning the color of the hiding containers: same versus different colors) x 2 (rotation angle: $90^{\circ}$ versus $180^{\circ}$ ) design; all factors were manipulated within subjects. Each of the resulting eight conditions included four trials, presented in a blocked manner (in total: 32 trials). The trials of each rotation angle were also blocked and presented in two sessions on two different days within one week to account for the children's limited attention span. The order of the conditions and of the trials per condition and as well as the side where the object was hidden (left vs. right) was counterbalanced following a Latin square. To exclude local enhancement effects, the experimenter always touched both cups when hiding the object, while it was balanced within each condition whether he first touched the hiding cup or the other cup that would remain empty. The turning direction of the board (i.e., to the left or to the right) was counterbalanced between children. The number of correct trials per condition served as dependent variable. Trials were counted as correct if the child touched the correct hiding container. The procedure was video recorded and the behavior of six randomly chosen children was rated by a second rater, yielding an interrater reliability of $r(6)=1.00(p<.001)$.

Each child was tested individually in a quiet room, either in the institution or in a lab at the university. The caregiver was present in the room and told not to help the child or to give any hints. In the familiarization phase, the child was allowed to play with the cups and the toys, and to choose the most preferred toy, which served as target object in the whole experiment. Thereafter, a probe trial followed testing simple object permanence. In the probe trial, the object was placed beneath one of the two cups but the board was not rotated, and the 
child was encouraged to search for the object. All children solved this trial successfully. Thereafter, 16 test trials involving one rotation angle (either $90^{\circ}$ or $180^{\circ}$ ) followed (i.e., four trials for each of the four combinations of the color-shape conditions). In the second session on a different day, the 16 test trials involving the alternative rotation angle were presented. In the test trials, the child first observed the experimenter hiding the toy beneath one of the two cups, followed by rotating the board. He then immediately prompted the child to search for the toy. The child's decision was recorded and the experimenter lifted the chosen cup that either contained the toy that was then handed to the child or was empty.

Insert Figure 1 about here

\section{Results}

A preliminary analysis revealed no significant effects of sex, order of the eight conditions, or location of the differently colored or shaped containers on children's general performance, $p \mathrm{~s}$ $>$.47. Data were thus accumulated across these variables.

First, we tested whether children found the hidden object significantly more often than expected by chance, which was the case in all conditions (see Table 1; Holm correction for multiple testing), except for the condition in which the shape and color of the containers were identical and the containers were rotated by $180^{\circ}$. Here, children performed on chance level.

Insert Table 1 about here

To analyze whether the discriminability of the shape and color of the containers, and rotation angle yielded significant effects on children's success in finding the hidden object, a 2 (discriminability concerning the shape of the hiding containers: same versus different shapes) $\mathrm{x} 2$ (discriminability concerning the color of the hiding containers: same versus 
Running head: TWO-YEAR-OLDS' SPATIAL SEARCH

different colors) $\mathrm{2}$ (rotation angle: $90^{\circ}$ versus $180^{\circ}$ ) ANOVA with repeated measures was computed, with the number of correct trials per condition as dependent variable. It revealed significant main effects of the discriminability of the shape, $F(1,27)=6.10, p=.020, \eta_{\mathrm{p}}{ }^{2}=$ .18 , and of rotation angle, $F(1,27)=4.25, p=.049, \eta_{\mathrm{p}}{ }^{2}=.14$. The discriminability of the color did not affect children's performance, $p=.43$, and no interactions were significant, $p \mathrm{~s}>$ .37. Thus, children found the hidden object significantly more often when the shape of the two hiding containers was different than when it was the same, and when the containers were rotated by $90^{\circ}$ than by $180^{\circ}$ (see Fig. 2).

Insert Figure 2 about here

Finally, we examined whether different colors and / or different shapes of the containers prevented children from an inhibition bias in trials involving $90^{\circ}$ rotations. It was tested for each of the four conditions involving $90^{\circ}$ rotations whether the children chose the closer container more often than expected by chance (i.e., more often than in two of the four trials per condition). One-sample $t$ - ests revealed a significant inhibition bias in all conditions (see Table 2). Thus, children of our sample had a clear tendency to reach for the closer container after $90^{\circ}$ rotations that was hardly attenuated by additional color or shape information.

Insert Table 2 about here

\section{Discussion}

The aim of the present study was to examine whether 2-year-olds are able to solve spatial rotation tasks if the task requirements were simplified by enhancing the visual discriminability of the hiding containers in terms of different shapes and colors, and by 
varying the rotation angle. Children performed above chance level in all conditions, except for the condition in which the two containers had the same shape and color and were rotated by $180^{\circ}$. Most importantly, there was a main effect of the discriminability of the shapes of the containers on children's performance: Children reached more often for the correct container when the containers had different shapes than when they had the same shape. However, children did not profit from the containers having different colors (see Ebersbach \& Nawroth, 2016, for similar results). These findings suggest that young children do benefit from visually different hiding locations in spatial rotation tasks, but that color seems to be a less salient characteristic than shape for young children (see also Fernandez \& Richman, 1979; Kagan \& Lemkin, 1961; Wilcox, 1999). Thus, differently shaped containers help children to find the objects hidden beneath these containers more reliably.

The stronger salience of shape over color is supported by findings showing that infants rather rely on shape than on other object properties in a great variety of tasks. For instance, 4month-olds infer from shape, not from color, whether only one or two adjacent objects are presented (Needham, 1999). In addition, 4-month-olds use shape and size to individuate objects - and only later in their development, at about 11.5 months, they also rely on color (Wilcox, 1999; Wilcox, Wood, \& Chapa, 2008; Woods \& Schuler, 2014; Xu \& Carey, 1996; $\mathrm{Xu}$ et al., 2004). The reliance on shape is also closely related to children's lexical development. Children usually first acquire words referring to shape than words referring to color (e.g., Bornstein, 1985; Heibeck \& Markman, 1987; Modreski \& Goss, 1969). Moreover, as children start to acquire words for objects (i.e., in their second year of life), they pay more attention to the shape of objects when identifying them (e.g., Colunga \& Smith, 2005; Imai, Gentner \& Uchida, 1994; Keil, 1994; Pereira \& Smith, 2009). Thus, during the rapid growth of the lexicon, words for shape play a special role (Gershkoff-Stowe \& Smith, 2004), even though color is also a relevant dimension in object recognition in toddlers (Perry \& Saffran, 2017). Other studies showed that also older children (and adults) categorize objects rather 
Running head: TWO-YEAR-OLDS' SPATIAL SEARCH

according to their shape than other features such as color (Diesendruck \& Bloom, 2003; Landau, Smith, \& Jones, 1988), which has been termed "shape bias" (cf. Samuelson \& Bloom, 2008). Several reasons for the dominance of shape over color have been assumed (Macario, 1991). First, color can be perceived by one sensory modality only (i.e., visually), while shape can additionally be explored tactually. Second, color is less predictive for most events and object functions (except of food) than shape. Third, the shape of solid objects is relatively stable across different contexts while the color / shading may vary depending on lighting conditions.

Besides the salience of shape, one might also speculate that children in the present study benefitted from different shapes of the containers only because they learned to associate the hidden object with a particular shape of the container in each trial, retrieving its final position by recalling this shape (i.e., object-shape association). However, several issues contradict this explanation. First, the shape of the hiding containers was balanced across trials so that the object-shape association would have had to be adjusted repeatedly for each of the 32 trials, which is rather improbable at this young age. Second, associative learning is based on reinforcement / punishment, which occurred in our paradigm always at the end of each trial, after the child reached to a cup, which was then lifted. If the cup was empty, this can be conceived as punishment; if the object appeared there, this can be conceived as reinforcement. If a child, in fact, learned by this mechanism to associate a certain container with the object and applied this association to the next trial, it was very likely not successful as we systematically varied under which container the object was hidden. Third, if the children solved the task in fact by simple association, no effects of rotation angle should emerge as children should associate the target with a particular container, independently of whether it was rotated by $90^{\circ}$ or $180^{\circ}$. However, our results revealed a better performance after $90^{\circ}$ than after $180^{\circ}$ rotations. Thus, children's success in the spatial rotation task cannot solely be attributed to simple association learning but is more likely because visually distinct containers 
supported children in maintaining their mental representation of the hidden object by ruling out conflicting information (i.e., identical containers).

Another finding was a main effect of rotation angle: Children performed significantly better after $90^{\circ}$ rotations than after $180^{\circ}$ rotations. This is in line with previous findings, suggesting that young children have problems tracking rotated, hidden objects when the configuration of the hiding locations appears identical before and after the rotation (e.g., Barth \& Call, 2006; Ebersbach \& Nawroth, 2016; for similar results with dogs, see Miller, Gipson, Vaughan, Rayburn-Reeves, \& Zentall, 2009). Moreover, a $180^{\circ}$ rotation might also provoke committing an egocentric error (e.g., Campos, Anderson, Barbu-Roth, Hubbard, Hertenstein, \& Witherington, 2000; Piaget \& Inhelder, 1948) in terms of reaching to the side (relative to the child's body) where the object was lastly seen. This error is prevented by the changed spatial configuration after a $90^{\circ}$ rotation. However, as the egocentric-to-allocentric shift, which is closely related to infants' crawling experiences (Bremner, 1978), occurs largely between 11 to 16 months of age (Acredolo, 1978), the egocentric tendency in spatial search should have been rather small in our sample of 24-month-olds. Nevertheless, even 4-year-olds tend to rely on egocentric cues in spatial search when they are presented with conflicting allocentric information, while no such egocentric error occurs when no conflict exists (Vasilyeva, 2002). Thus, the use of egocentric cues is not only a question of age but also a question of contextual characteristics of the spatial task. Other research suggested that older children use different strategies when being confronted with $90^{\circ}$ and $180^{\circ}$ rotations. Vander Heyden, Huizinga, Raijmakers, and Jolles (2017) examined the ability of 8- to 12-year-olds to navigate through a model city, built of a plate with blocks as houses. Contrary to our results, children were less accurate and slower when the models were rotated by $90^{\circ}$ compared to $180^{\circ}$. The authors explained this by assuming that children used an egocentric self-rotation approach for $90^{\circ}$ rotations but an inversion of the axes in terms of flipping, without mentally rotating their own position, for $180^{\circ}$ rotations. Thus, a larger rotation angle can also be a 
Running head: TWO-YEAR-OLDS' SPATIAL SEARCH

facilitation when another, more effective strategy than mental rotation is used (cf. Ebersbach \& Krüger, 2016; Murray, 1997). Given that children in our sample were much younger than in the study of Vander Heyden et al. (2017), they might not have been able to apply such an effective strategy and probably relied, instead, on a more simplified and more error-prone strategy - such as the changed spatial configuration, as discussed above.

Moreover, the $90^{\circ}$ and $180^{\circ}$ rotations also differed with regard to another aspect: The duration of the $90^{\circ}$ rotation was shorter than the $180^{\circ}$ rotation, so that the spatial memory had to be stored for a shorter duration (Hespos et al., 2009). However, the different durations of the rotations cannot fully explain the better performance after $90^{\circ}$ rotations compared to $180^{\circ}$ rotations as children in the study of Okamoto-Barth and Call (2008) performed better after $360^{\circ}$, which took longer, compared to $180^{\circ}$ rotations. On the other hand, $360^{\circ}$ rotations might be easier as the hidden object is at the same location before and after the rotation. Thus, whether the effect of rotation angle can be attributed to the changed configuration and / or to the duration of the rotation requires further research. Interestingly, the only condition in which children performed on chance level in the present study was the condition in which the two containers had the same color, same shape and were rotated by $180^{\circ}$. Thus, here the initial configuration and the configuration after the rotation were maximally similar, undermining children's spatial abilities.

A final aim of this study was to assess whether an inhibition bias, that is children's tendency after $90^{\circ}$ rotations to reach significantly more often for the closer (but in $50 \%$ of the trials empty) container than for the farther container, could be attenuated by the visual discriminability of the containers (cf. Ebersbach \& Nawroth, 2016). Contrary to our predictions, children in the present study showed the inhibition bias in all conditions: Neither different shapes nor different colors of the containers (nor both) prevented them from reaching for the empty closer cups in incorrect trials. Interestingly, the inhibition bias disappeared among 30-month-olds in the study by Ebersbach and Nawroth (2016) in the 
"different colors" condition. One important aspect that might explain the difference between this and our study is the age of the children, who were on average six months younger in the present study. Inhibition abilities are poor in general at a young age (e.g., Diamond, 1990; Diamond \& Doar. 1989; Kochanska, Coy, \& Murray, 2001; Sophian \& Sage, 1985) and younger children therefore might have more difficulties to suppress a dominant action (i.e., reaching for the closer container) instead of executing a better planned action (i.e., reaching for the farther container after passing the closer container with their hand) in spatial rotation tasks. Our results suggest that inhibition abilities might develop with regard to this particular task at the age between 24 and 30 months, as the inhibition bias did not occur for 30-montholds and hiding containers with different colors, whereas 2-year-olds could not prevent the bias even when additional cues were given (i.e., different colors or different shapes).

In conclusion, we showed that 2-year-olds are already able to solve simple spatial transformation tasks above chance level and benefit from hiding containers that differ in shape, but not from hiding containers that differ in color. The latter finding suggests that tasks assessing young children's (spatial) abilities might profit from simplifying the tasks for the children, as it allows detecting a specific ability at an earlier age. Simplifying here does not refer to the ability to be tested (i.e., tracking hidden, rotated objects) but to the design of the task: Test characteristics can be adjusted in order to focus children's attention on the relevant aspects and to unburden their working memory. It is, for instance, conceivable that children would profit from visually discriminable containers not only in spatial rotation tasks but also in spatial transposition tasks, in which successful searches have not been found before the age of 42 months (Sophian, 1984). Moreover, the advantage of visually discriminable containers did not prevent children from the inhibition bias. Thus, even if children performed above chance after $90^{\circ}$ rotations, they still had a tendency to reach for the closer but empty container in incorrect trials, which can be explained by immature executive functions at this age (e.g., Kochanska et al., 2001). Finally, the finding that 2-year-olds did not profit from differently 


\section{Running head: TWO-YEAR-OLDS' SPATIAL SEARCH}

colored containers is in line with other studies suggesting that shape but not color is a salient dimension at this age (e.g., Fernandez \& Richman, 1979). 
Running head: TWO-YEAR-OLDS' SPATIAL SEARCH

\section{References}

Acredolo, L. P. (1978). Development of spatial orientation in infancy. Developmental Psychology, 14(3), 224-234. doi: 10.1037/0012-1649.14.3.224.

Aguiar, A., \& Baillargeon, R. (1999). 2.5-month-old infants' reasoning about when objects should and should not be occluded. Cognitive Psychology, 39, 116-157. doi: 10.1006/cogp.1999.0717

Barth, J., \& Call J. (2006). Tracking the displacement of objects: A series of tasks with Great Apes (Pan troglodytes, Pan paniscus, Gorilla gorilla, and Pongo pygmaeus) and young children (Homo sapiens). Journal of Experimental Psychology: Animal Behavior Processes, 32, 239-252. doi: 10.1037/0097-7403.32.3.239

Berthier, N. E., Bertenthal, B. I., Seaks, J. D., Sylvia, M. R., Johnson, R. L., \& Clifton, R. K. (2001). Using object knowledge in visual tracking and reaching. Infancy, 2, 257-284. doi: 10.1207/S15327078IN0202_9

Bornstein, M. H. (1985). Colour-name versus shape-name learning in young children. Journal of Child Language, 12, 387-393. doi: 10.1111/j.1749-6632.1990.tb48913.x

Boudreau, J. P., \& Bushnell, E. W. (2000). Spilling thoughts: Configuring attentional resources in infants' goal-directed actions. Infant Behavior \& Development, 23, 543566. doi: 10.1016/S0163-6383(01)00059-5

Bremner, J. G. (1978). Egocentric versus allocentric spatial coding in nine-month-old infants: Factors influencing the choice of code. Developmental Psychology, 14(4), 346-355. doi: 10.1037/0012-1649.14.4.346.

Butler, S. C., Berthier, N. E., \& Clifton, R. K. (2002). Two-year-olds' search strategies and visual tracking in a hidden displacement task. Developmental Psychology, 38, 581-590. doi: $10.1037 / 0012-1649.38 .4 .581$ 
Running head: TWO-YEAR-OLDS' SPATIAL SEARCH

Call, J. (2001). Object permanence in orang utans (Pongo pygmaeus), chimpanzees (Pantroglodytes), and children (Homo sapiens). Journal of Comparative Psychology, 115, 159-171. doi: 10.1037/0735-7036.115.2.159

Campos, J. J., Anderson, D. I., Barbu-Roth, M. A., Hubbard, E. M., Hertenstein, M. J., \& Witherington, D. (2000). Travel broadens the mind. Infancy, 1, 149-219. doi: 10.1207/S15327078in0102_1.

Colunga, E., \& Smith, L. B. (2005). From the lexicon to expectations about kinds: A role for associative learning. Psychological Review, 112, 347-382. doi: 10.1037/0033295X.112.2.347

Diamond, A. (1990). Developmental time course in human infants and infant monkeys, and the neural bases of inhibitory control in reaching. Annals of the New York Academy of Sciences, 608, 637-676.

Diamond, A., \& Doar, B. (1989). The performance of human infants on a measure of frontal cortex function, the delayed response task. Developmental Psychobiololgy, 22, 271294. doi: $10.1002 / \mathrm{dev} .420220307$

Diamond, A., \& Lee, E. (2000). Inability of five-month-old infants to retrieve a contiguous object: A failure of conceptual understanding or of control of action? Child Development, 71, 1477-1494. doi: 10.1111/1467-8624.00241

Diesendruck, G., \& Bloom, P. (2003). How specific is the shape bias? Child Development, 74, 168-178. doi: 10.1111/1467-8624.00528

Ebersbach, M., \& Krüger, M. (2016). View makes a difference: Presenting human figures from the back or front affects mental spatial transformations of children and adults. Spatial Cognition \& Computation, 16, 173-191. doi: 10.1080/13875868.2015.1124109

Ebersbach, M., \& Nawroth, C. (2016). The effects of visual discriminability and rotation angle on 30-month-olds' search performance in spatial rotation tasks. Frontiers in Developmental Psychology, 7, 1648. doi: 10.3389/fpsyg.2016.01648 
Estes, D. (1998). Young children's awareness of their mental activity: The case of mental rotation. Child Development. 69, 1345-1360. doi: 10.1111/j.1467-8624.1998.tb06216.x

Fernandez, B. W., \& Richman, C. L. (1979). Discrimination learning in preschool children as a function of the stimulus and relevant dimension. Journal of Psychology, 102, 289-298. doi: $10.1080 / 00223980.1979 .9923500$

Frick, A. \& Möhring, W. (2013) Mental object rotation and motor development in 8- and 10-month-old infants. Journal of Experimental Child Psychology, 115, 708-720. doi: 10.1016/j.jecp.2013.04.001

Garrad-Cole, F., Lew, A. R., Bremner, J. G., \& Whitaker, C. J. (2001). Use of cue configuration geometry for spatial orientation in human infants (Homo sapiens). Journal of Comparative Psychology, 115, 317-320. doi:10.1037//0735-7036.115.3.317

Gershkoff-Stowe, L., \& Smith, L. B. (2004). Shape and the first hundred nouns. Child Development, 75, 1-17. doi: 10.1111/j.1467-8624.2004.00728.x

Haun, D. B., Call, J., Janzen, G., \& Levinson, S. C. (2006). Evolutionary psychology of spatial representations in the hominidae. Current Biology, 16, 1736-1740. doi:10.1016/j.cub.2006.07.049

Heibeck, T. H., \& Markman, E. M. (1987). Word learning in children: An examination of fast mapping. Child Development, 58, 1021-1034. doi: 10.2307/1130543

Herrmann, E., Call, J., Hernandez-Lloreda, M. V., Hare, B., \& Tomasello, M. (2007). Humans have evolved specialized skills of social cognition: The Cultural Intelligence Hypothesis. Science, 317, 1360-1366. doi:10.1126/science.1146282

Hespos, S. J., \& Baillargeon, R. (2001). Reasoning about containment events in very young infants. Cognition, 78, 207-245. doi: 10.1016/S0010-0277(00)00118-9

Hespos, S., Gredebäck, G., von Hofsten, C., \& Spelke, E. S. (2009). Occlusion is hard: Comparing predictive reaching for visible and hidden objects in infants and adults. Cognitive Science, 33, 1483-1502. doi: 10.1111/j.1551-6709.2009.01051.x 
Running head: TWO-YEAR-OLDS' SPATIAL SEARCH

Imai, M., Gentner, D., \& Uchida, N. (1994). Children's theories of word meaning: The role of shape similarity in early acquisition. Cognitive Development, 9, 45-75. doi:

10.1016/0885-2014(94)90019-1

Kagan, J., \& Lemkin, J. (1961). Form, color and size in children's conceptual behavior. Child Development, 32, 25-28. doi: 10.2307/1126169

Keil, F. C. (1994). The birth and nurturance of concepts by domains: the origins of concepts of living things. In L. A. Hirschfeld \& S. A. Gelman (Eds.). Mapping the mind: Domain specificity in cognition and culture (pp. 1234-1254). New York: Cambridge University Press.

Kochanska, G., Coy, K. C., \& Murray, K. T. (2001). The development of self-regulation in the first four years of life. Child Development, 72, 1091-1111. doi: 10.1111/j.14676494.2006.00421.x

Landau, B., Smith, L. B., \& Jones, S. S. (1988). The importance of shape in early lexical learning. Cognitive Development, 3, 299-321. doi: 0.1016/0885-2014(88)90014-7

Macario. J. (1991). Young children's use of color in classification: Foods and canonically colored objects. Cognitive Development, 6, 17-46. doi: 10.1016/0885-2014(91)90004-W

Marmor G. S. (1975). Development of kinetic images: When does the child first represent movement in mental images? Cognitive Psychology, 7, 548-559. doi: 10.1016/00100285(75)90022-5

Miller, H. C., Gipson, C. D., Vaughan, A., Rayburn-Reeves, R., \& Zentall, T. R. (2009). Object permanence in dogs: Invisible displacement in a rotation task. Psychonomic Bulletin \& Review, 16, 150-155. doi:10.3758/PBR.16.1.150

Modreski, R. A. \& Goss, A. E. (1969). Young children's initial and changed names for form-color stimuli. Journal of Experimental Child Psychology, 8, 402-409. doi: 10.1016/0022-0965(69)90112-X 
Moore, D. S., \& Johnson, S. P. (2008). Mental rotation in human infants: a sex difference. Psychological Science, 19, 1063-1066. doi:10.1111/j.1467-9280.2008.02200.x Murray, J. E. (1997). Flipping and spinning: Spatial transformation procedures in the identification of rotated natural objects. Memory \& Cognition, 25, 96-105. doi:10.3758/BF03197287

Needham, A. (1999). The role of shape in 4-month-old infants' object segregation. Infant Behavior and Development, 22, 161-178. doi:10.1016/S0163-6383(99)00008-9

Okamoto-Barth, S., \& Call, J. (2008). Tracking and inferring spatial rotation by children and great apes. Developmental Psychology, 44, 1396-1408. doi:10.1037/a0012594

Oláh, K., Kupán, K., Csík, A., Király, I., \& Topál, J. (2015). Feature or location? Infants and adults adopt different strategies to search for a hidden toy in an ambiguous task. Infant Behavior \& Development, 41, 73-79. doi:10.1016/j.infbeh.2015.08.003

Pereira, A., \& Smith, L. B. (2009). Developmental changes in visual object recognition between 18 and 24 months of age. Developmental Science, 12, 57-80. doi: 10.1111/j.1467-7687.2008.00747.x

Perry, L. K., \& Saffran, J. R. (2017). Is a pink cow still a cow? Individual differences in toddlers' vocabulary knowledge and lexical representations. Cognitive Science, 41(4), 1090-1105. doi:10.1111/cogs.12370.

Piaget, J. (1955). The Child's Construction of Reality. London: Routledge \& Kegan Paul.

Piaget, J., \& Inhelder, B. (1948). La Representation de l'Espace chez l'Enfant. Paris: Presses Universitaires de France.

Rosander, K., \& von Hofsten, C. (2004). Infants' emerging ability to represent occluded object motion. Cognition, 91, 1-22. doi: 10.1016/S0010-0277(03)00166-5

Samuelson, L. K., \& Bloom, P. (2008). The shape of controversy: What counts as an explanation of development? Developmental Science, 11, 183-184. doi: 10.1111/j.14677687.2007.00663.x 
Running head: TWO-YEAR-OLDS' SPATIAL SEARCH

Sophian, C. (1984). Spatial transpositions and the early development of search.

Developmental Psychology, 20, 21-28. doi:10.1037/0012-1649.20.1.21

Sophian, C., \& Sage, C. (1985). Infants' search for hidden objects: Developing skills for using information selectively. Infant Behavior and Development, 8, 1-14. doi: 10.1016/S01636383(85)80012-6

Van de Walle, G., Carey, S., \& Prevor, M. (2000). Bases for object individuation in infancy: Evidence from manual search. Journal of Cognition and Development, 1, 249-280. doi: 10.1207/S15327647JCD0103_1

Wilcox, T. (1999). Object individuation: Infants' use of shape, size, pattern, and color. Cognition, 72, 125-166. doi:10.1016/S0010-0277(99)00035-9

Wilcox, T., \& Baillargeon, R. (1998a). Object individuation in infancy: The use of featural information in reasoning about occlusion events. Cognitive Psychology, 37, 97-155. doi: 10.1006/cogp.1998.0690

Wilcox, T., \& Baillargeon, R. (1998b). Object individuation in young infants: Further evidence with an event monitoring task. Developmental Science, 1, 127-142. doi: $10.1111 / 1467-7687.00019$

Wilcox, T., Woods, R., \& Chapa, C. (2008). Color-function categories that prime infants to use color information in an object individuation task. Cognitive Psychology, 57, 220261. doi: 10.1016/j.cogpsych.2008.02.001

Woods, R. J., \& Schuler, J. (2014). Experience with malleable objects influences shape-based object individuation by infants. Infant Behavior \& Development, 37, 178-186. doi:10.1016/j.infbeh.2014.01.005

Xu, F., \& Carey, S. (1996). Infants metaphysics: The case of numerical identity. Cognitive Psychology, 30, 111-153. doi: 10.1006/cogp.1996.0005

Xu, F., Carey, S., \& Quint, N. (2004). The emergence of kind-based object individuation in infancy. Cognitive Psychology, 49, 155-190. doi:10.1016/j.cogpsych.2004.01.001 
Running head: TWO-YEAR-OLDS' SPATIAL SEARCH

Table 1

Mean number of correct trials per condition, and results of t-tests analyzing whether children's performance was above chance (i.e., more than two correct trials out of four per condition).

\begin{tabular}{|c|c|c|c|c|c|c|c|}
\hline & Condition & & & & & & \\
\hline Shape & Color & $\begin{array}{c}\text { Rotation } \\
\text { angle }\end{array}$ & $M$ & $S D$ & $t$ & $d f$ & $p$ \\
\hline \multirow[t]{4}{*}{ same } & same & $90^{\circ}$ & 2.89 & 1.07 & 4.43 & 27 & $<.01 * *$ \\
\hline & & $180^{\circ}$ & 2.39 & 1.13 & 1.83 & 27 & .078 \\
\hline & different & $90^{\circ}$ & 2.89 & 0.99 & 4.75 & 27 & $<.01 * *$ \\
\hline & & $180^{\circ}$ & 2.71 & 1.18 & 3.20 & 27 & $<.05^{*}$ \\
\hline \multirow[t]{4}{*}{ different } & same & $90^{\circ}$ & 3.14 & 0.80 & 7.53 & 27 & $<.01 * *$ \\
\hline & & $180^{\circ}$ & 2.82 & 1.28 & 3.40 & 27 & $<.01 * *$ \\
\hline & different & $90^{\circ}$ & 3.18 & 0.98 & 6.34 & 27 & $<.01 * *$ \\
\hline & & $180^{\circ}$ & 2.75 & 1.00 & 3.95 & 27 & $<.01 * *$ \\
\hline
\end{tabular}

Note. Max.: 4; adjusted $p$-values after Holm correction. 
Running head: TWO-YEAR-OLDS' SPATIAL SEARCH

Table 2

Inhibition bias per condition

\begin{tabular}{llccccc}
\hline \multicolumn{2}{c}{ Condition } & & & & & \\
\hline Shape & Color & $M$ & $S D$ & $t$ & $d f$ & $p$ \\
\hline same & same & 2.68 & .94 & 3.80 & 17 & $<.001^{* * *}$ \\
& different & 2.46 & .92 & 2.66 & 19 & $<.05^{*}$ \\
\hline different & same & 2.50 & .84 & 3.15 & 17 & $<.01^{* *}$ \\
& different & 2.53 & .79 & 3.78 & 14 & $<.001^{* * *}$
\end{tabular}

$\overline{\text { Note. } M \text { refers to the mean number of reaches to the closer container after } 9} 0^{\circ}$ rotations (max. number of trials per condition: 4). Adjusted $p$-values after Holm correction. 
Running head: TWO-YEAR-OLDS' SPATIAL SEARCH

\section{Figure captions}

Figure 1. Schematic depiction of the rotating board with the two hiding containers, beneath one of which an object is hidden (child's view; "different color / different shape" condition).

Figure 2. Mean number of correct trials per condition. Note. Bars indicate standard errors. 
Running head: TWO-YEAR-OLDS' SPATIAL SEARCH

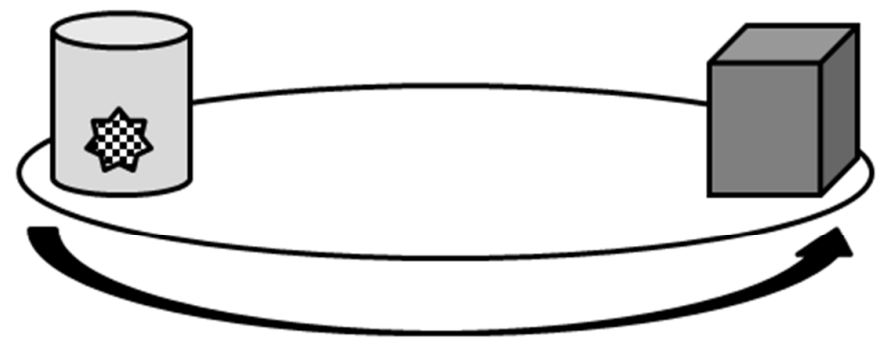

Figure 1. 
Running head: TWO-YEAR-OLDS' SPATIAL SEARCH

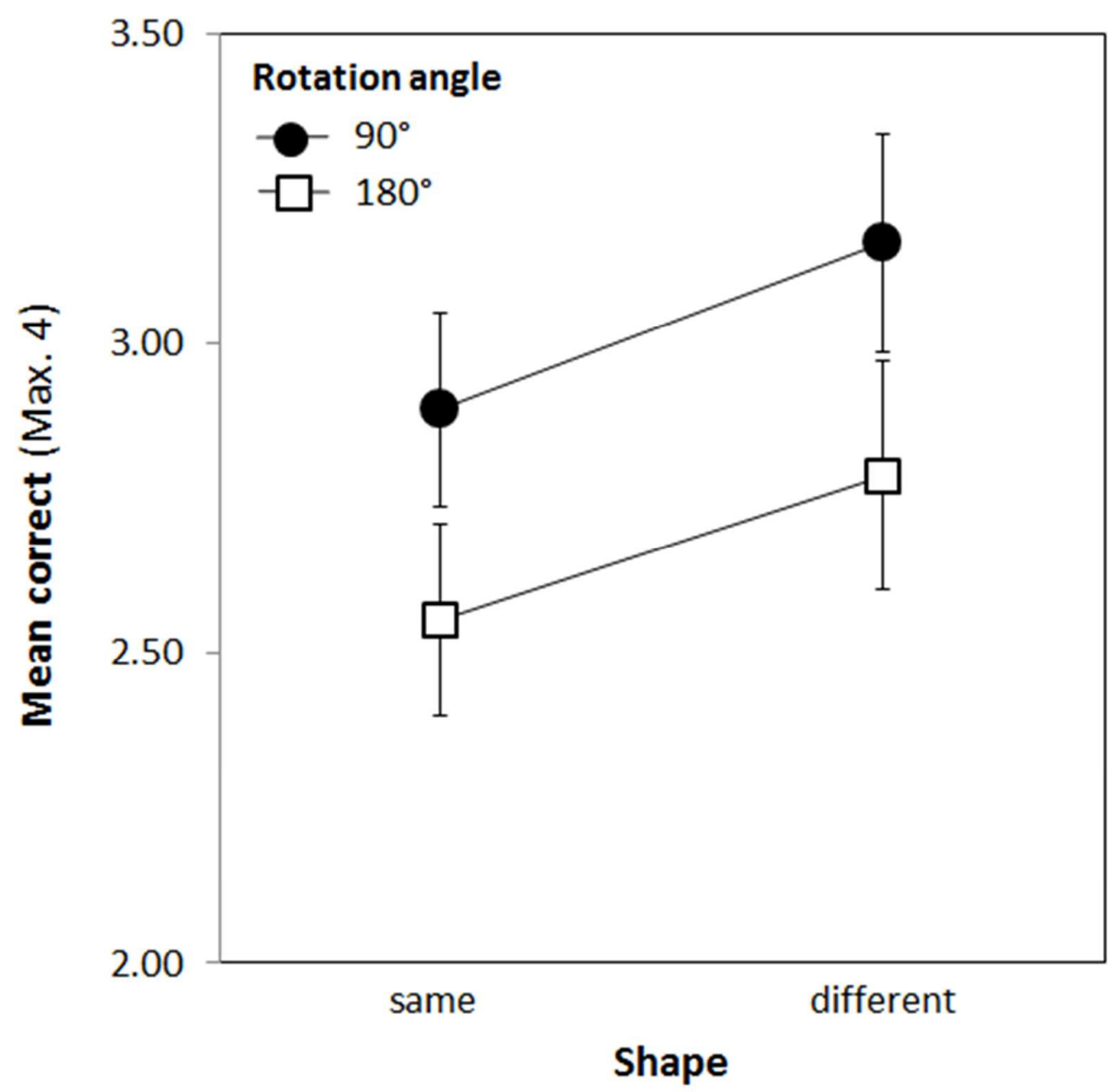

Figure 2. 